\title{
FORMAÇÃO DE PROFESSORES E INTEGRAÇÃO PEDAGÓGICA DAS TECNOLOGIAS DA INFORMAÇÃO E DA COMUNICAÇÃO (TIC): DA USABILIDADE TÉCNICA AO LETRAMENTO DIGITAL
}

\author{
TEACHER EDUCATION AND PEDAGOGICAL INTEGRATION OF INFORMATION \\ AND COMMUNICATIONS TECHNOLOGIES (ICT): FROM TECHNICAL USABILITY \\ TO DIGITAL LETTERING
}

Patrícia Margarida Farias Coelho ${ }^{1}$

Doutora em Comunicação e Semiótica. Pontifícia Universidade Católica de São Paulo - PUC-SP Coordenadora do Mestrado Interdisciplinar em Ciências Humanas. Universidade de Santo Amaro - UNISA Professora permanente do Programa de Pós-graduação em Educação. Universidade Metodista de São Paulo - UMESP São Paulo, São Paulo, Brasil. patriciafariascoelho@gmail.com

Marcos Rogério Martins Costa Doutor em Letras. Universidade de São Paulo - USP Pós-doutorando no Mestrado Nacional Profissional de Ensino de Física .Instituto de Física da Universidade de Brasília - IF/UnB Membro da Equipe multidisciplinar. Centro de Educação a Distância da Universidade de Brasília - Cead/UnB Brasília, Distrito Federal - Brasil. marcosrmcosta15@gmail.com

Everson Luiz Oliveira Motta

Mestre em Educação. Centro Universitário Internacional - UNINTER Doutorando em Educação e Currículo. Pontifícia Universidade Católica de São Paulo - PUC-SP Curitiba, Paraná - Brasil. soneve@gmail.com

Resumo: O objetivo deste artigo é explorar a formação continuada de professores, problematizando, pelo viés da Pedagogia Social (VIEIRA, 2016; VIEIRA; VIEIRA, 2015), a integração pedagógica das Tecnologias da Informação e da Comunicação (TIC). É um estudo inicial de investigação, de caráter exploratório, conforme Marconi e Lakatos (2003). Esta é uma pesquisa do domínio da Tecnologia Educativa (TE), porque situa as TIC em prol da função educativa e não simplesmente utilitária. Metodologicamente, este trabalho está segmentado em duas partes. Primeiramente, discutimos a formação continuada de professores e o contexto de uso das tecnologias e acesso à internet no Brasil. Em um segundo momento, exploramos o conceito de usabilidade (NIELSEN, 1990, 1993; SILIUS; TERVAKARI; POHJOLAINEN, 2003), propondo um modelo em que as TIC estejam conciliadas ao conceito de letramento digital, uma vez que a usabilidade pedagógica compreende as práticas sociais do usuário - seja ele aluno ou professor - para além dos aspectos determinados pela interação imediata entre homem e máquina. Eis o percurso que almejamos promover na formação continuada de professores no que se refere ao uso das TIC em sala de aula: da usabilidade técnica ao letramento digital.

Palavras-chave: educação; letramento digital; pedagogia social; tecnologia; usabilidade.

\begin{abstract}
The aim of this article is to explore the continuing education of teachers, questioning, through the bias of Social Pedagogy (VIEIRA, 2016; VIEIRA; VIEIRA, 2015), the pedagogical integration of Information and Communication Technologies (ICT). It is an initial research study, of an exploratory nature, according to Marconi and Lakatos (2003). It is a research in the field of Educational Technology (ET), because it places ICT on behalf of the educational function and not simply utilitarian. Methodologically, this work is segmented into two parts. Firstly, we discussed the continuing education of teachers and the context of use of technologies and Internet access in Brazil. Secondly, we explore the concept of usability (NIELSEN, 1990, 1993; SILIUS; TERVAKARI; POHJOLAINEN, 2003), proposing a model in which ICTs are reconciled with the concept of digital literacy, since pedagogical usability comprises practices of the user - being student or teacher - apart from the aspects determined by the immediate interaction between man and machine. Here is the course that we seeks to promote in the ongoing teacher education regarding the use of ICT in the classroom: from technical usability to digital literacy.
\end{abstract}

Keywords: education; digital literacy; social pedagogy; technology; usability.

Para citar - (ABNT NBR 6023:2018)

COELHO, Patrícia Margarida Farias; COSTA, Marcos Rogério Martins; MOTTA, Everson Luiz Oliveira. Formação de professores e integração pedagógica das Tecnologias da Informação e da Comunicação (TIC): da usabilidade técnica ao letramento digital. Eccos - Revista Científica, São Paulo, n. 58, p. 1-20, e11014, jul./set. 2021. Disponível em: https://doi.org/10.5585/eccos.n58.11014.

\footnotetext{
${ }^{1}$ Possui auxílio do Projeto de Pesquisa da Fundação de Amparo à Pesquisa do Estado de São Paulo, intitulado "Formação de Professores e Tecnologias Digitais aplicadas à Educação". Processo Nº. 2018/07133-0. CAAE: 31771220.2.0000.5508.
} 


\title{
Introdução
}

\begin{abstract}
As inovações tecnológicas, que despontam no mundo globalizado da mídia eletrônica, estão implicando em conformações diferenciadas da vida social contemporânea e levando a ressignificações de conceitos, tais como o de infância, juventude, velhice, família, inclusão ou exclusão social e muitos outros, pois remodelam sociedades e identidades em todo o mundo (ZUIN, 2010, p. 962).
\end{abstract}

No Brasil, os avanços tecnológicos dos últimos anos não foram acompanhados pelos planejamentos educacionais em diversos aspectos (COELHO; COSTA; MATTAR, 2018). Temos um público cada vez mais conectado às redes de computadores e às mídias sociais e, por outro lado, um caminhar caudaloso e moroso no cenário nacional em favor da expansão e da integração pedagógica das Tecnologias da Informação e da Comunicação (TIC). Diversos estudos nacionais recentemente publicados têm apontado a necessidade de se repensar o letramento, os usos das TIC e a atuação dos professores (BONILLA; PRETO, 2015; FARR, 2014; GIACOMAZZO, 2015; OLIVEIRA; GIACOMAZZO, 2017; SOUZA, 2007). No cenário internacional não é diferente, pois os estudos de Hackett, Pahl e Pool (2017), Rose (2015) e Webster e Gunter (2018) asseveram, cada um à sua maneira e por distintos prismas teóricos, a premência de se explorar as TIC e de não mais desassociá-las dos fatores educacionais e sociais.

A formação de professores continuada pode cumprir um papel relevante para modificar esse cenário, pois, como previa o patrono da Educação brasileira, Paulo Freire, "se o meu compromisso é realmente com o homem concreto, com a causa de sua humanização, de sua libertação, não posso por isso mesmo prescindir da ciência, nem da tecnologia, com as quais me vou instrumentando para melhor lutar por esta causa" (FREIRE, 2002, p. 22).

A proposta freiriana é a de que os processos de ensino e de aprendizagem não sejam apartados um do outro, mas considerados em conjunto, pois, onde não há aprendizagem também não existe ensino, conforme Freire (2002). Outro aspecto a se considerar, nessa concepção educacional, indica que o processo de ensino-aprendizagem é uma mediação entre o conhecimento escolarizado e as bagagens cultural e identitária de cada indivíduo - seja ele professor ou aluno.

As TIC não podem ser consideradas como ferramentas secundárias, plano de fundo ou algum equipamento suplementar. Se quisermos, de fato, a integração pedagógica, as TIC devem participar do fazer social, didático e instrucional do professorado. É nessa direção que este trabalho desenvolve seus argumentos, pois a finalidade deste artigo é problematizar a formação continuada dos professores na perspectiva da Pedagogia Social, em interface com outros estudos (HALL, 1998; KENSKI, 2013; LANKSHEAR; KNOBEL, 2008). 
A partir da consideração do prisma social, desenvolve-se a corrente da Pedagogia Social. Conforme explica Vieira (2016, p. 107), a mediação sociopedagógica pode servir de

[...] ferramenta de transformação deste olhar monocultural e etnocêntrico, que começa muito cedo a ser incorporado nas crianças e jovens, na família, na escola e entre pares. Neste sentido, a Pedagogia Social tem que ser operacionalizada para transformar este olhar que teima em ver a diferença como deficiência.

Segundo a autora, o olhar monolítico é derivado de uma monocultura que constrói uma concepção deturpada das diferenças. Nessa contracorrente,

[...] o homem é um animal classificador, observa a alteridade, inclui-a nos seus pares, na medida em que se identifica ou exclui-a, usando como fronteira da identidade uma classificação feita pela negativa, autocentrada e/ou estigmatizadora do(s) outro(s). [...] E, portanto, uma inclusão leva, inevitavelmente, a uma exclusão (VIEIRA; VIEIRA, 2015, p. 229).

Ao considerar essa perspectiva, não utilizamos no título deste trabalho a expressão inclusão pedagógica das TIC, mas preferimos integração pedagógica das TIC. No processo de inclusão, um corpo estrangeiro/estranho passa a fazer parte de um conjunto pré-existente, enquanto que, no processo de integração, há a "incorporação de um corpo a um conjunto" (HOUAISS, 2014). Portanto, o problema de pesquisa deste artigo reafirma que as TIC não devem ser coadjuvantes no plano pedagógico do professorado, mas parte integrada e integrante desse plano - mesmo porque, como Zuin (2010) esclarece em nossa epígrafe, as inovações tecnológicas remodelam sociedades e as próprias identidades em todo o mundo. Para tanto, exploramos a temática das TIC em dois aspectos específicos: o da usabilidade técnica, considerado no âmbito da prática, e o do letramento digital, compreendido no campo do social.

Como objetivo, exploramos a formação continuada de professores, problematizando, pelo viés da Pedagogia Social (VIEIRA, 2016; VIEIRA; VIEIRA, 2015), a integração pedagógica das TIC. Para tanto, abordamos processo de ensino-aprendizagem com as TIC e seus desafios. É um estudo inicial de investigação de natureza exploratória, conforme classificam Marconi e Lakatos (2003).

Esses autores esclarecem que o estudo exploratório se define como "investigações de pesquisa empírica cujo objetivo é a formulação de questões ou de um problema" (MARCONI; LAKATOS, 2003, p. 187). Comumente, esse tipo de investigação possui três finalidades: “desenvolver hipóteses, aumentar a familiaridade do pesquisador com um ambiente, fato ou fenômeno, para a realização de uma pesquisa futura mais precisa ou modificar e clarificar conceitos" (p. 187). A primeira finalidade é dominante nesta pesquisa, uma vez que o conceito de usabilidade não é oriundo da área da Educação, mas sim das Tecnologias da Informação 
(TI). Neste estudo, estamos fazendo uma ponte entre essas duas áreas a partir da utilização didático-pedagógica do conceito de usabilidade aplicado no espaço educacional. Em direção semelhante à proposta de Lijnse (1995), propomos uma pesquisa de desenvolvimento como um caminho para uma estrutura didática da ciência, no caso das TI no campo da Educação. Dessa maneira, a proposta metodológica deste trabalho se refere a uma pesquisa do domínio da Tecnologia Educativa (TE), porque situa as TIC em prol da função educativa e não simplesmente utilitária (AKKER, 1999).

Metodologicamente, este trabalho está segmentado em duas partes. Em um primeiro momento, discutimos a formação continuada de professores e o contexto de uso das tecnologias e acesso à internet no Brasil. Em seguida, exploramos o conceito de usabilidade (NIELSEN, 1990, 1993; SILIUS; TERVAKARI; POHJOLAINEN, 2003), propondo um modelo em que as TIC estejam conciliadas ao conceito de letramento digital, uma vez que a usabilidade pedagógica compreende as práticas sociais do usuário - seja ele aluno ou professor - para além dos aspectos determinados pela interação imediata entre homem e máquina.

\section{Formação continuada de professores e contexto brasileiro}

Para Tardif e Raymond (2000), a formação do professor parte de uma prática reflexiva que compreende os conhecimentos e as experiências prévias dos docentes com o intuito de propor aprendizados em seus contextos de atuação profissional. De acordo com Libâneo (1998), a profissão de professor deve combinar tanto elementos teóricos quanto situações práticas reais pertencentes ao cotidiano. Sob o prisma de Nóvoa (2017), tornar-se professor é transformar uma predisposição numa disposição pessoal.

Para se entender a profissão do professor, é necessário investigar suas características como profissional da educação e seu contexto de trabalho. Diversos são os estudos que se dedicaram a (re)contextualizar e a desmistificar o papel do professor na sociedade contemporânea (cf. AGUILAR; ARJONA; NORIEGA, 2015; DOURADO; OLIVEIRA; SANTOS, 2007; HUBERMAN, 1992). A partir desses estudos, entende-se que, não raras vezes, almeja-se construir um ideal de professor, o qual, em virtude das incongruências da sociedade contemporânea, liquefaz-se. Compreendendo os estudos sobre identidade, podemos inferir por que o ideal de professorado não se sustenta e como este se (des)constrói no processo de formação docente.

Deve-se considerar também a sociedade contemporânea na qual vive o professor do século XXI, que não é um todo unificado e monolítico, como em diversos momentos dos 
séculos anteriores. Cada grupo socioeconômico compreendeu e ressignificou o papel do docente em sua vida. Por exemplo, a profissão de professor já foi concebida em diferentes perspectivas socioculturais: como religioso (jesuíta), um membro da família ("tio", "tia"), um vocacionado (“missão de educar"), um mentor, um tutor, dentre outras. Desde o fim do século XX, problematiza-se o conceito de identidade que, conforme Hall (1998), pode ser entendida da seguinte forma:

O sujeito, previamente vivido como tendo uma identidade unificada e estável, está se
tornando fragmentado; composto não de uma única, mas de várias identidades
algumas vezes contraditórias e não resolvidas. Correspondentemente, as identidades
que compunham as paisagens sociais "lá fora" e que asseguravam nossa conformidade
subjetiva com as "necessidades" objetivas da cultura estão entrando em colapso, como
resultado de mudanças estruturais e institucionais. O próprio processo de
identificação, pelo qual nos projetamos em nossas identidades culturais, tornou-se
mais provisório, variável e problemático (HALL, 1998, p. 12).

Nessa perspectiva de investigação da experiência de vida, Huberman (1992) propõe entender a carreira docente em fases como em um ciclo da existência. Esse estudo, embora ainda traga um ideal de professorado, já aponta que a carreira docente é composta por momentos de continuidade (construção e estabilização) e de ruptura (diversificação). Desse modo, compreende-se que o docente é um profissional da educação que está em transformação e, portanto, abona nossa proposta de entendê-lo em sua multiplicidade de papéis, na linha do pensamento de Hall (1998).

Torna-se, portanto, pertinente considerar a formação inicial do docente, em que o sujeito aprende a ressignificar a prática pedagógica, ora sanando suas dúvidas, ora experimentando o cotidiano da sala de aula (GOMES; MARINS, 2004). No estágio do ciclo de experiência docente, o professor está adquirindo conhecimentos, práticas didáticas e também criando seu repertório pessoal de propostas teórico-metodológicas, conforme aponta Huberman (1992).

Se, na formação inicial, o professor está no estágio de aquisição, exploração e experimentação (HUBERMAN, 1992; NÓVOA, 2017), na formação continuada, o professorado possui outros objetivos, bem como outras habilidades e competências. A formação continuada de professores é um processo mais complexo e envolve fatores, responsabilidades e comportamentos distintos daqueles necessários na formação inicial. Conforme defende Nóvoa (2017), a atividade docente exige uma formação continuada e atenta às demandas dos alunos e das próprias instituições de ensino e pesquisa.

Por isso, a formação continuada de professores tem como objetivo garantir a atuação professoral, bem como promover a aprendizagem significativa no circuito professor-objeto de conhecimento-aluno (cf. DAY, 2001). De acordo com Nóvoa (1992, p. 37), “os momentos de 
balanço retrospectivos sobre os percursos pessoais e profissionais são em que cada um produz a sua vida". No caso dos professores, esse é também o momento de (re)construir a sua profissão.

Segundo Almeida (2006), Gatti (2010) e Pimenta (2013), a formação continuada é um processo por meio do qual os professores reveem, renovam e ampliam, individual ou coletivamente, a sua prática docente. É nesse momento que o professorado pode rever, revisitar e aprimorar suas práticas pedagógicas, adquirindo, desenvolvendo e criticando sua atuação pessoal dentro e fora da sala de aula. Por isso, escolhemos a formação continuada para abordar neste artigo, pois ela garante que os professores formados anteriormente ao advento da popularização da internet entenderão sobre a relevância das TIC no processo contemporâneo de ensino e aprendizagem, bem como reforça essa pertinência para aqueles que concluíram seus estudos do ensino superior no século $\mathrm{XXI}^{2}$.

Um dos desafios da formação continuada de professores é oferecer uma experiência educacional que acolha o cotidiano da sala de aula. Para tanto, o professorado deve estar preparado para ser protagonista de suas próprias escolhas, assumindo responsabilidades por sua trajetória acadêmica e, direta e indiretamente, influenciar as políticas educativas em seu contexto de trabalho. Nesse ponto, é bom salientar que a situação de trabalho do professorado brasileiro possui algumas barreiras. De acordo com a pesquisa da Fundação Telefônica/Vivo $(2015)^{3}$, temos os seguintes obstáculos para se efetivar uma educação conectada:

- a precariedade da infraestrutura física das escolas públicas no Brasil;

- as dificuldades de cunho burocrático, especialmente as de alterar o currículo definido no âmbito do governo federal;

- os critérios de acesso ao ensino superior, uma vez que o vestibular, na medida em que pauta o ensino (sobretudo no nível médio), impõe uma série de amarras e limitações às possíveis abordagens (FUNDAÇÃO TELEFÔNICA/VIVO, 2015, p. 109).

Outros fatores podem ser citados, que também obstaculizam o trabalho com as TIC no cotidiano do professorado:

- ausência de uma política que regule todas as instituições educacionais do País sobre como elas devem integrar as TIC aos seus planos de ensino;

- alto custo para manter uma conexão rápida de acesso à internet e difundi-la em todo o espaço escolar;

\footnotetext{
${ }^{2}$ Em uma próxima publicação, vamos explorar a formação inicial dos professores e a importância da relação das TIC com os objetos de ensino. Por isso, não abordamos esses aspectos neste artigo. Todavia, não poderíamos nos furtar de indicar a relevância dessa associação.

3 O estudo realizado pela Fundação Telefônica/ Vivo, em sua segunda edição, foi feito com jovens de 15 a 29 anos provenientes de todas as regiões do país (FUNDAÇÃO TELEFÔNICA/VIVO, 2015).
} 
- dificuldade em implementar e gerenciar a governança e a administração escolar em relação ao uso dos computadores e do acesso à internet;

- inabilidade do alunado para com as TIC, nas funções mais complexas dos softwares básicos (Word, Excel, PowerPoint);

- congestionamento durante o compartilhamento de computadores, tablets e outras TIC com os demais membros da unidade escolar, sendo raro o uso personalizado do equipamento, gerando, comumente, filas de espera, constrangimento, desinteresse, dentre outras dificuldades.

Os recursos tecnológicos fazem parte das ferramentas didáticas do docente. Por isso, o contexto no qual se insere o professorado deve ser considerado e suas dificuldades devem ser também avaliadas. No campo mais amplo, o País tem uma perspectiva mais positiva (cf. COELHO; COSTA; MATTAR, 2018), principalmente no que se refere à quantidade de pessoas conectadas.

No dia 21 de fevereiro de 2018, foi divulgado de forma inédita pelo Instituto Brasileiro de Geografia e Estatística (IBGE) um estudo sobre o uso das TIC e o acesso à internet nos domicílios brasileiros. As informações difundidas fazem parte da Pesquisa Nacional por Amostra de Domicílios Contínua (Pnad C) e tem como referência o quarto trimestre de 2016. Nesse estudo, foi constatado que 64,7\% dos brasileiros com idade acima de 10 anos estavam conectados à internet em 2016, o que equivale a 116 milhões de pessoas.

Por outro lado, 63,3\% não acessaram a internet em 2016. Segundo o IBGE, os dois maiores motivos são: 37,8\% não sabiam como usar e 37,6\% não tinham interesse. Isso quer dizer que três em cada quatro pessoas não estão conectadas porque não sabem usar as ferramentas on-line ou não têm interesse nelas. A terceira justificativa é a de que o serviço de internet é muito oneroso para a sua renda, sendo essa a explicação de $14,3 \%$ dos brasileiros desconectados.

Observa-se, assim, a relevância do professorado e das instituições de ensino para a democratização das habilidades e das competências a fim de se utilizar as TIC. Isso acontece porque sem o conhecimento sobre os usos e as potencialidades das TIC o desinteresse é cada vez maior. É um círculo vicioso: o desconhecimento gera o desinteresse, e o inverso também é correto, pois o desinteresse estimula o desconhecimento sobre as tecnologias digitais.

Embora seja a primeira vez que o IBGE faz um detalhamento dos usos das TIC, desde 2012, o instituto verifica o acesso à internet nos domicílios brasileiros. Tabulamos os dados dos Pnads de 2012 a 2016 no seguinte gráfico: 


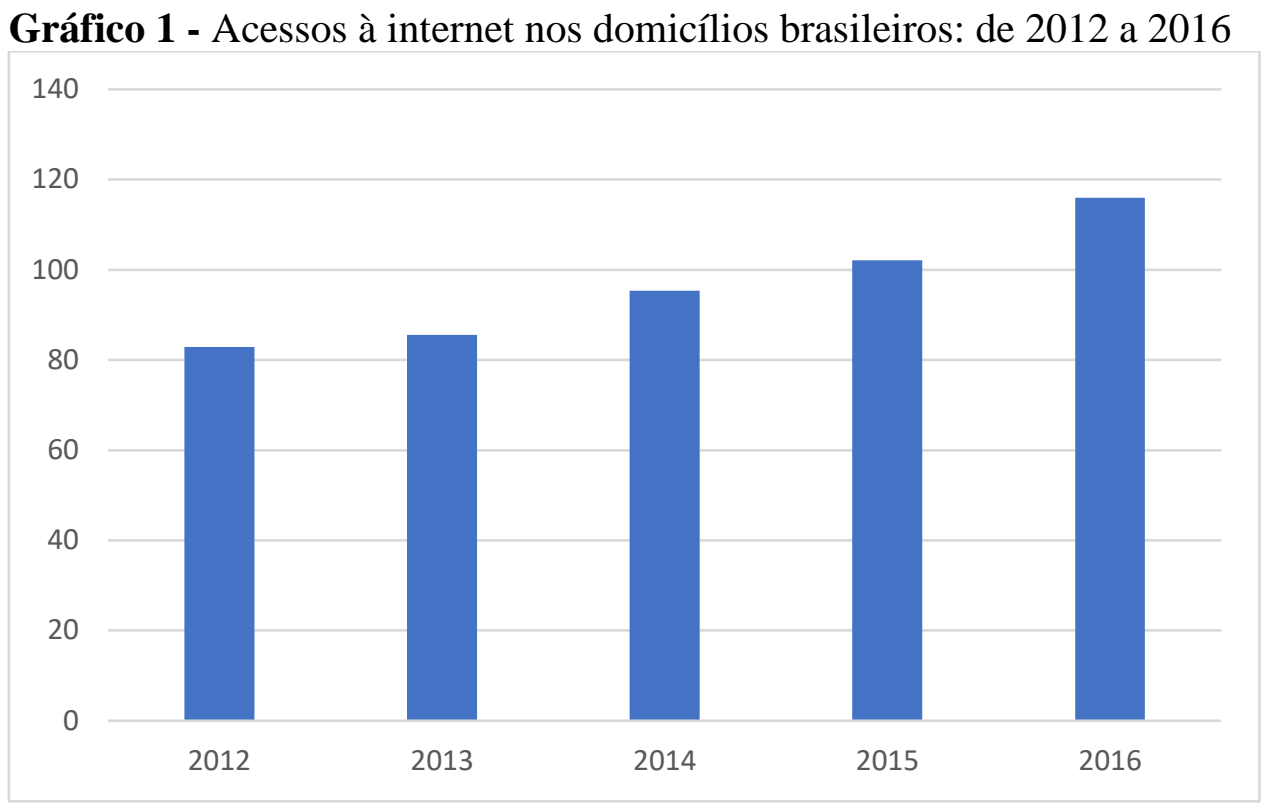

Fonte: Pnad (IBGE, 2018).

O acesso à internet nos domicílios brasileiros vem aumentando: de 81,1 milhões, em 2012, para 116 milhões, em 2016. Além disso, comparando os dados de 2015 com os de 2016, depreende-se que, em $2015,57,5 \%$ da população estava conectada e, em 2016, passou para 64,7\%. Ou seja, saiu de 102,1 milhões para 116 milhões de brasileiros conectados. Esse novo contingente de brasileiros conectados equivale a 13,9 milhões de pessoas, correspondendo a uma população maior do que a de Portugal, que possui 10,3 milhões de habitantes, segundo os números oficiais divulgados em 2017.

Todos esses dados demonstram que a formação continuada precisa capacitar os docentes para atender esse montante de brasileiros que passaram a estar conectados. Além disso, é preciso observar as TIC com um novo olhar, não ignorando as dificuldades apontadas, mas fazendo delas pautas para serem discutidas nas reuniões pedagógicas, nos fóruns municipais, estaduais e federais. De forma geral, pela perspectiva da pedagogia social, propomos desvelar os aspectos socioculturais e, sobretudo, sociais que permeiam a formação docente. Para além de um formalismo que estabeleça parâmetros rígidos e metas abstratas, discutimos nesse tópico o contexto mais próximo e mais amplo em que o professorado se insere, desde suas principais dificuldades até os dados oficiais de sua nação. 


\section{Letramento digital e desafios da usabilidade pedagógica}

Para refletirmos sobre o letramento digital, é imprescindível retomarmos o conceito de letramento. A distinção entre alfabetização e letramento começou a ser desenvolvida no Brasil a partir dos anos 1970. Essa frente teórica tomou força com os estudos de Freire (2002), os quais problematizaram o reconhecimento dos códigos linguísticos, discutindo sobre se estes últimos seriam ou não suficientes para o educando utilizar todo o potencial da comunicação nas mais diversas linguagens. Retomando estudos anteriores (SOARES, 1998, 2003), Soares (2004, p. 6) explica as facetas do conceito de letramento no contexto brasileiro.

De acordo com Soares (2003), a partir da segunda metade do século XX, houve o surgimento concomitante, em diversos e diferentes contextos culturais e econômicos, de conceitos mais complexos para designar práticas sociais oriundas dos atos de escrever e de ler. Segundo a autora, “[...] é em meados dos anos de 1980 que se dá, simultaneamente, a invenção do letramento no Brasil, do illettrisme, na França, da literacia, em Portugal, para nomear fenômenos distintos daquele denominado alfabetização, alphabétisation" (SOARES, 2004, p. 7). Diante desse contexto, depreende-se que a perspectiva social perpassa cada cultura e política educacional, influindo direta e indiretamente na construção das teorias e propostas voltadas à Educação.

No território nacional, o conceito de letramento se associa ao de alfabetização, pois, como alerta Soares (2004, p. 7), "no Brasil os conceitos de alfabetização e letramento se mesclam, se superpõem, frequentemente se confundem". Para comprovar essa relação, a autora destaca as mudanças da concepção de instrução nos censos brasileiros ao longo das últimas décadas do século XX:

As alterações no conceito de alfabetização nos censos demográficos, ao longo das décadas, permitem identificar uma progressiva extensão desse conceito. A partir do conceito de alfabetizado, que vigorou até o Censo de 1940, como aquele que declarasse saber ler e escrever, o que era interpretado como capacidade de escrever o próprio nome; passando pelo conceito de alfabetizado como aquele capaz de ler e escrever um bilhete simples, ou seja, capaz de não só saber ler e escrever, mas de já exercer uma prática de leitura e escrita, ainda que bastante trivial, adotado a partir do Censo de 1950; até o momento atual, em que os resultados do Censo têm sido frequentemente apresentados, sobretudo nos casos das Pesquisas Nacionais por Amostragem de Domicílios (PNAD), pelo critério de anos de escolarização, em função dos quais se caracteriza o nível de alfabetização funcional da população, ficando implícito nesse critério que, após alguns anos de aprendizagem escolar, o indivíduo terá não só aprendido a ler e escrever, mas também a fazer uso da leitura e da escrita, verifica-se uma progressiva, embora cautelosa, extensão do conceito de alfabetização em direção ao conceito de letramento: do saber ler e escrever em direção ao ser capaz de fazer uso da leitura e da escrita (SOARES, 2004, p. 7). 
Depreende-se, assim, que a alfabetização está associada à aquisição do significado dos códigos de linguagem, enquanto que o processo de letramento está relacionado às práticas sociais que envolvem a linguagem como um todo. De acordo com Silva (2011, p. 109), "a perspectiva de 'iletrado' como o sujeito a quem foram negadas a justiça social e as mais altas posições nas relações de poder, fez surgir o termo letramento com uma perspectiva social". Como explicam os estudos de Kleiman (1995, 2007), o letramento constrói, como objeto de conhecimento, os aspectos e os impactos sociais da linguagem em suas diversas modalidades e tipos de manifestação.

Kleiman (2007) ressalta que, mesmo tendo origem acadêmica, o conceito de letramento se assentou no discurso escolar. Isso ocorreu, conforme explica a estudiosa, porque, em primeiro lugar, desvinculou-se dos estudos da língua escrita, compreendendo que os usos e as práticas escolares vão muito além do ato de ler e escrever. Com isso, demonstrou-se que existem diversas e distintas práticas de letramento para além da prática de alfabetização, "tida como única e geral, mas apenas uma das práticas de letramento da nossa sociedade, embora possivelmente a mais importante, até mesmo pelo fato de ser realizada pela também mais importante agência de letramento, a instituição escolar" (KLEIMAN, 2007, p. 1-2).

É por isso que consideramos o letramento digital como mais um dos multiletramentos que o alunado e o professorado devem vivenciar no processo de ensino-aprendizagem. Esclarecemos que o professor não necessariamente deve conhecer todos os mecanismos e todas as funcionalidades de um aparato tecnológico para fazer uso pedagógico dele. Nem mesmo deve saber todas as teorias e todas as propostas sobre letramento para executar um plano de ensino que integre as TIC. O que estamos defendendo é que o professorado possa fazer uso consciente das TIC em sua didática e metodologia de ensino sem menosprezá-las ou supervalorizá-las.

Como indica Kleiman (2007, p. 7), devemos assumir "o letramento, ou melhor, os múltiplos letramentos da vida social, como o objetivo estruturante do trabalho escolar em todos os ciclos". Com a formação continuada dos professores, não deve ser diferente: o processo de letramento teórico e prático tem de continuar depois da formação inicial no ensino superior. Claro que, com outros objetivos e com distintos níveis de complexificação e didatismo, os múltiplos letramentos continuam ao longo de toda a vida.

Concordamos com Rojo e Melo (2017, p. 1272) quando as estudiosas ressaltam que as práticas letradas específicas baseadas no uso de diversas e múltiplas tecnologias digitais trouxeram para "a cena das teorias de gêneros (textuais, discursivos) novos desafios. Não somente os textos/enunciados em ambientes digitais se organizam de novas maneiras, como 
hipertextos e hipermídias, combinando multissemioticamente uma variedade de linguagens". O letramento digital deriva dessas práticas letradas em ambiente digital, pois essas "novas práticas letradas", como salientam Rojo e Melo (2017, p. 1272), "obedecem a um novo ethos e a novas mentalidades". E o professorado deve estar preparado para participar delas, compartilhando e interagindo com elas dentro e fora da sala de aula.

Lankshear e Knobel (2008) afirmam que o letramento digital faz parte de um conjunto maior de novos letramentos. Para esses autores, os novos letramentos surgiram de uma série de mudanças que aconteceram nos últimos anos com o advento das novas tecnologias, em especial aquelas que nasceram com a internet (cf. LÉVY, 2010; SANTAELLA, 2010). Essas mudanças, segundo os estudiosos, afetaram as experiências vividas por todos os setores da sociedade: trabalho, lazer, família e, consequentemente, educação. Por letramento digital, entendemos as práticas letradas associadas às TIC e ao ambiente digital. Esse tipo de letramento propõe ao professorado a utilização, com finalidade pedagógica, das ferramentas tecnológicas em suas possibilidades múltiplas e em diferentes plataformas digitais.

Dentre as diversas possibilidades de desenvolver o letramento digital (OLIVEIRA; GIACOMAZZO, 2017; PETARNELLA; SOARES, 2010; ROJO; MELO, 2017, dentre outros), optamos por desdobrar esse processo a partir do conceito de usabilidade. A escolha por essa perspectiva se deve à produtividade dessa noção no seio da área do design e do desenvolvimento de aparatos tecnológicos. Com isso, queremos aproximar a área da Educação à das TIC, pois, com a interdisciplinaridade, promove-se "uma convergência, uma complementaridade, o que significa, de um lado, a transferência de conceitos teóricos e de metodologias e, de outro, a combinação de áreas" (FIORIN, 2008, p. 38).

O termo usabilidade é utilizado no âmbito das TIC, em específico no campo de design e de desenvolvimento de softwares e plataformas digitais, para auxiliar a medir o grau de satisfação de um usuário na realização de uma determinada tarefa efetuada pela tecnologia digital. Conforme Nielsen (1990), nesse domínio, deve-se considerar a usabilidade como um dos vários objetivos dos sistemas informatizados, como, por exemplo, velocidade de conclusão da tarefa, taxa de erro, retenção e armazenamento de dados, dentre outros. No design de softwares, a usabilidade é definida como "o fator que assegura que os produtos sejam fáceis de usar, eficientes e agradáveis, da perspectiva do usuário" (PREECE; ROGERS; SHARP, 2005, p. 35).

A ISO 9241:11 (1998) determina a medida da usabilidade para os softwares, conhecida como usabilidade de design. A normativa prescreve que a usabilidade é "a capacidade de um produto de ser usado por usuários específicos para atingir objetivos específicos com eficácia, 
eficiência e satisfação em um contexto específico de uso". Nesse documento, a eficácia, a eficiência e a satisfação estabelecem as diretrizes do conceito de usabilidade. A eficácia é medida com a capacidade do usuário em concluir a tarefa. A eficiência é medida a partir do tempo gasto pelo usuário durante a efetivação da tarefa. A satisfação é calculada por meio das atitudes positivas ou negativas do usuário no software, como responder ou não aos questionários de avaliação exibidos pelo próprio sistema. Neste artigo, deslocamos esse conceito para o âmbito do social, com enfoque ao processo de ensino-aprendizagem, desdobrando os conceitos de usabilidade pedagógica e usabilidade técnica (NIELSEN, 1990, 1993; SILIUS; TERVAKARI; POHJOLAINEN, 2003; SILVA; GOMES, 2015).

Conforme a classificação de Nielsen (1990), para um software ser bem acolhido pelo público-alvo, ele tem de seguir uma série de critérios de aceitabilidade que devem ser pensados na etapa da produção e não somente na da recepção. Essa cadeia de critérios é discriminada na forma de uma cascata de subcomponentes. Quanto mais alto o subcomponente, mais abstrato, mais geral e mais complexo, porque implica em todo o desenvolvimento da cadeia, exigindo mais recursos econômicos, criativos e de gerenciamento. Quanto mais baixo o subcomponente, mais concreto, mais específico e mais simples, no sentido de envolver setores mais especializados da empresa.

Nessa série, a noção de usabilidade representa um dos subcomponentes da utilidade, sendo que este é o quinto subcomponente geral da série. A utilidade é o patamar que verifica se o software atende aos objetivos a que se propôs. Dentro da utilidade, está, de um lado, a usabilidade associada aos diversos empregos que o usuário faz no sistema do software e a utilidade, que como subcomponente específico, designa a funcionalidade do software, isto é, a correspondência entre a ação do software e a tarefa que lhe foi atribuída pelo usuário.

Silius, Tervakari e Pohjolainen (2003), membros do Laboratório de Hipermídia do Instituto de Mídia Digital da Universidade de Tecnologia Tampere (Finlândia), adaptaram esse modelo de Nielsen (1990, 1993). Na perspectiva desses pesquisadores, a usabilidade se subdivide em usabilidade técnica e usabilidade pedagógica. $\mathrm{Na}$ adaptação desses pesquisadores finlandeses, conforme comentam Silva e Gomes (2015), a usabilidade está totalmente inserida no subcomponente de utilidade. O diferencial é que a noção está desdobrada, pois os finlandeses verificaram que os usos com finalidade pedagógica são distintos daqueles que estão voltados ao funcionamento padrão do software. 
Figura 1 - Usabilidade: de Nielsen (1990, 1993) a Silius, Tervakari e Pohjolainen (2003)

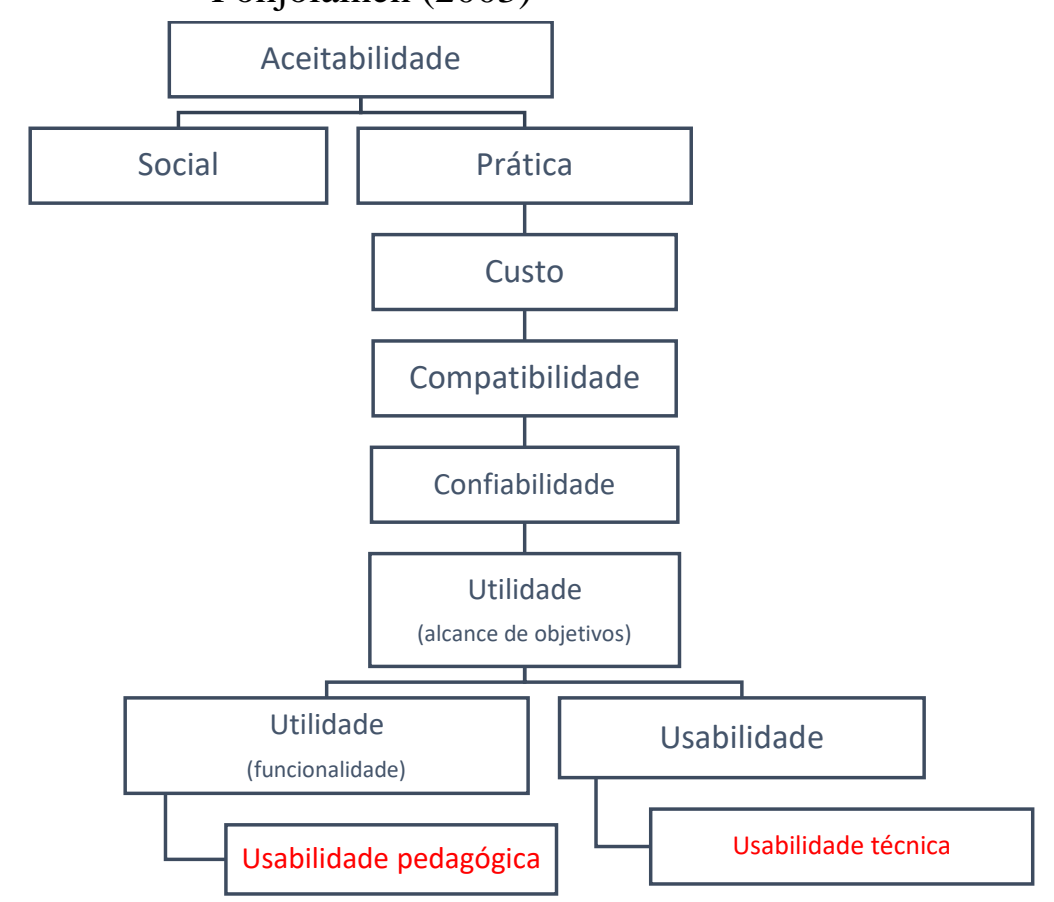

Fonte: Proposta por Nielsen $(1990,1993)$ e adaptado por Silius; Tervakari; Pohjolainen (2003) e Silva e Gomes (2015).

Na adaptação de Silius, Tervakari e Pohjolainen (2003), a usabilidade técnica fica reservada para o subcomponente da usabilidade, no sentido conferido por Nielsen (1990), isto é, atribuído aos vários usos que se pode fazer no sistema do software. Já a usabilidade pedagógica se associa à utilidade, como subcomponente específico, porque, na perspectiva dos pesquisadores finlandeses, a finalidade pedagógica atrela-se à funcionalidade do software, isto é, dá objetivos pedagógicos, paradidáticos e didáticos, que não necessariamente são pensados pelo produtor, mas que podem ser previstos nos modelos de desenvolvimento das TIC. Isso também pode ser indicado nos próprios modelos de ensino e aprendizagem, os quais têm a possibilidade de utilizar ferramentas, digitais ou não, de outras áreas do conhecimento.

Nesse modelo de Nielsen (1990, 1993), adaptado por Silius, Tervakari e Pohjolainen (2003), verificamos que há um diálogo entre o usuário e o sistema, uma vez que a usabilidade pedagógica está relacionada ao sistema e/ou material de aprendizagem, que podem ser estabelecidos entre o estudante e o professor em uma situação de ensino e aprendizagem. Nessa perspectiva, ainda vigora sob a égide do macrocomponente da prática, isto é, nesse prisma, a usabilidade pedagógica depende da relação homem-máquina, mais do que a relação interpessoal para desenvolver sua atividade dentro do software.

A partir da Pedagogia Social (VIEIRA, 2016), propomos uma outra leitura para a usabilidade pedagógica. Esquematizamos na figura a seguir essa proposta: 
Figura 2 - Letramento digital e usabilidade pedagógica no macrocomponente do social

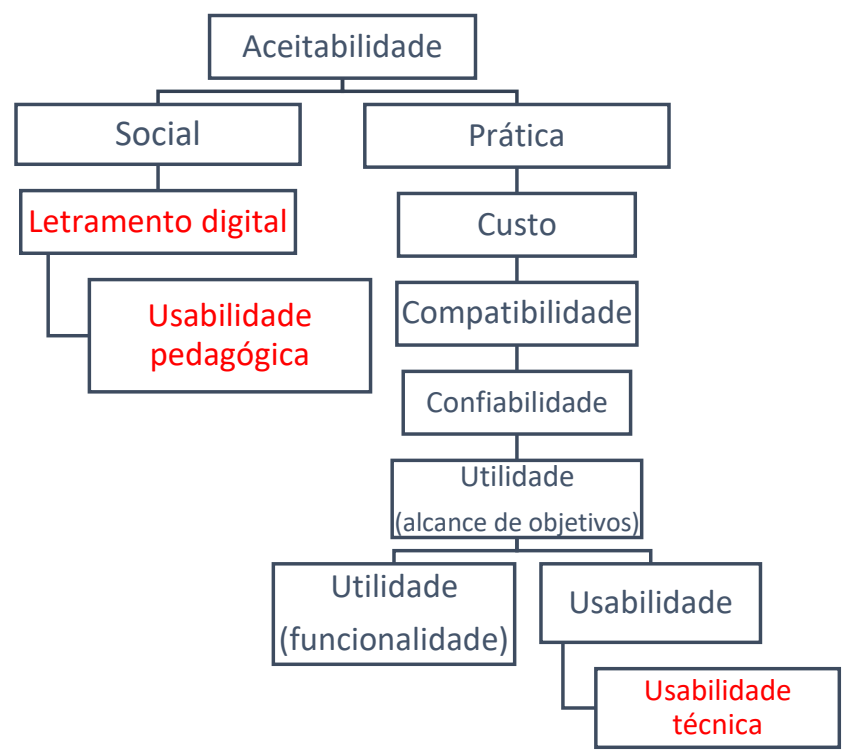

Fonte: Proposto por Nielsen (1990, 1993), Silius, Tervakari e Pohjolainen (2003), Silva e Gomes (2015) e adaptado pelos autores deste artigo.

Concebemos, a partir dos estudos de Kleiman (2007), Rojo e Melo (2017) e Soares (2004), que o letramento digital é mais um dos múltiplos letramentos e, como tal, está associado às práticas sociais que envolvem o ler e o escrever. Seguindo essa linha de pensamento, a usabilidade pedagógica não está no âmbito do macrocomponente da prática no modelo de Nielsen (1990), que envolve a relação homem-máquina, mas no do social, que promove as relações interpessoais. É também nesse macrocomponente que está a usabilidade pedagógica, pois essa seria, em nossa proposta, parte do processo de letramento digital, sendo, portanto, um subcomponente.

Com essa adaptação indicada na Figura 2, a usabilidade técnica continuaria sendo atribuída à usabilidade, como subcomponente da utilidade, dando conta dos vários usos na interação homem-máquina. Já o ganho seria para a noção de usabilidade pedagógica que não ficaria restrita à dimensão da máquina, ampliando seu escopo para outras relações interpessoais.

Dessa maneira, propomos, na Figura 2, um deslocamento da usabilidade pedagógica para o campo do social, pois defendemos, amparados nos estudos da Pedagogia Social, que os diferentes usos que os estudantes fazem da tecnologia digital não são um problema, uma dificuldade ou uma aberração ao funcionamento dos softwares e plataformas. É a própria realização da usabilidade pedagógica que, como já intuíam os estudos dos pesquisadores finlandeses citados, podem estar previstos ou não pelos produtores, mas não devem ser 
desprezados pelos modelos de desenvolvimento de softwares - a nosso ver, nem pelos modelos de ensino e aprendizagem.

O professorado tem, assim, um ganho para a formação continuada dessa perspectiva teórico-metodológica de uso das TIC, pois pode apreender os aparatos tecnológicos pelo prisma de suas potencialidades pedagógicas e não necessariamente pelas suas funcionalidades técnicas. Por exemplo, somente transpor o que estava escrito na lousa para os slides de uma apresentação em PowerPoint é desprezar a usabilidade pedagógica em prol da usabilidade técnica, enquanto que usar a apresentação de slides em PowerPoint com recursos de áudio, vídeo e animação que não estão presentes na lousa padrão -, pode se tornar uma usabilidade pedagógica se o ministrante da aula integrar esses recursos ao plano de ensino, articulando os objetivos pedagógicos de sua sequência didática a essas características do aparato digital.

\section{Considerações finais}

Dentre as distintas propostas para desenvolver o letramento digital, escolhemos o conceito de usabilidade. A noção é pertinente porque ela relaciona, como discutimos no tópico anterior, tanto a dimensão prática (as TIC devem alcançar seus objetivos de uso, como usabilidade técnica), quanto a perspectiva social (cada uso das TIC determina direta ou indiretamente uma função social, como usabilidade pedagógica). Por isso, ao explorar esse conceito do processo de letramento digital, estamos trazendo à luz uma possibilidade de aplicação teórica da Pedagogia Social na interface Educação e TIC.

Neste artigo, o objetivo foi investigar a formação continuada de professores em perspectiva social, refletindo sobre o conceito de usabilidade e sua aplicabilidade na educação. Destacamos que a educação atual permite a integração das tecnologias digitais para a difusão e a aquisição de conhecimentos, colaborando, assim, na prática docente. Daí a importância de o professorado estar consciente e preparado para utilizar as TIC em suas sequências didáticas, principalmente depois da experiência educacional em período pandêmico que alterou, direta e indiretamente, a práxis docente em relação à educação a distância (COSTA; SOUSA, 2020).

Como apontamos no início, este é um estudo inicial que propõe explorar, no domínio da Educação, maneiras de aplicar os aparatos tecnológicos e, para tanto, parte de um conceito não convencional a esse campo: o de usabilidade. O diferencial da abordagem desdobrada neste estudo foi que ele não se esquivou de considerar o contexto social, seja o do professor, seja o das TIC. Esse prisma distingue-se do estudo de Silva (2011), que também investiga os 
letramentos da formação dos professores, mas não trata a corrente social como a principal, nem considera a distinção entre usabilidade pedagógica e usabilidade técnica. Defendemos um processo de ensino e aprendizagem com as TIC que não se embase apenas na relação homemmáquina, mas que considere os aspectos interpessoais.

Em geral, pais e educadores preocupam-se com o uso do instrumento digital em sala de aula porque ele pode ser reflexo de um modismo; ou eles pensam que o próprio aparato digital possa, por si só, substituir a presença do docente. Esses dois tipos de raciocínios são errôneos, visto que, no primeiro caso, os recursos tecnológicos são inferiorizados sem contemplar suas potencialidades; já no segundo caso, esses mesmos recursos são supervalorizados, esquecendose de que o professor cumpre vários papéis em uma sala de aula que, em muito, superam a atividade mecânica.

Além disso, a tecnologia, por si mesma, não garante a aprendizagem significativa. Para ser um instrumento pedagógico, a tecnologia precisa ser contextualizada, vivenciada e aplicada por um profissional que conheça tanto os aspectos técnicos do aparato (usabilidade técnica), quanto suas possibilidades didático-pedagógicas (usabilidade pedagógica). Enfim, educação e tecnologia precisam se conectar e, para tanto, a usabilidade pedagógica deve ser inserida em todo o sistema de ensino básico brasileiro. Para isso, deve fazer parte da formação inicial dos docentes e, depois, desenvolvida na formação continuada de professores.

\section{Referências}

AGUILAR, Guadalupe Noriega; ARJONA, Braulio Angulo; NORIEGA, Giséle Ângulo. La resiliencia en la educación, la escuela y la vida. Perspectivas docentes: textos y contextos, Tabasco, v. 58, p. 42-48, 2015. ISSN-e 0188-3313. Disponível em: https://dialnet.unirioja.es/servlet/articulo?codigo=6349252. Acesso em: 31 ago. 2021.

AKKER, Jan van Den. Principles and methods of development research. In: AKKER, Jan van Den. et al. (eds.) Design approaches and tools in education and training. Dordrecht: Kluwer Academic Publishers, 1999, p. 1-14.

ALMEIDA, Maria Elisabeth Bianconcini. A inclusão digital do professor: formação e prática pedagógica. São Paulo: Editora Articulação Universidade/Escola, 2006.

BONILLA, Maria Helena Silveira; PRETO, Nelson de Luca. Política educativa e cultura digital: entre práticas escolares e práticas sociais. Perspectiva, Florianópolis, v. 33, n. 2, p. 499-521, maio/ago. 2015. DOI: https://doi.org/10.5007/2175-795X.2015v33n2p499.

COELHO, Patrícia Margarida Farias; COSTA, Marcos Rogério Martins; MATTAR, João Augusto. Saber digital e suas urgências: reflexões sobre imigrantes e nativos digitais. 
Educação \& Realidade, Porto Alegre, v. 43, p. 1077-1094, 2018. DOI: https://doi.org/10.1590/2175-623674528.

COSTA, Marcos Rogério Martins; SOUSA, Jonilto Costa. Educação a Distância e Universidade Aberta do Brasil: reflexões e possibilidades para o futuro pós-pandemia. Revista Thema, v. 18, n. Especial, p. 124-135, 2020. DOI: https://doi.org/10.15536/thema .V18.Especial.2020.124-135.1832.

DAY, Christopher. Desenvolvimento profissional de professores: os desafios da aprendizagem/permanente. Porto: Porto Editora, 2001.

DOURADO, Luiz Fernandes; OLIVEIRA, João Ferreira de; SANTOS, Catarina de Almeida. A qualidade da educação: conceitos e definições. Série Documental: Textos para Discussão, v. 24, n. 22, p. 5-34. Brasília: INEP/MEC, 2007. Disponível em:

http://portal.inep.gov.br/informacao-da-publicacao/-

/asset_publisher/6JYIsGMAMkW1/document/id/490475. Acesso em: 31 ago. 2021.

FARR, Arnold L. Occupy Technology: uma leitura marcuseana da relação entre tecnologia e o potencial para mudança social. In: PUCCI, Bruno; FRANCO, Renato; GOMES, Luiz Roberto. Teoria crítica na era digital: desafios. EUA: University of Kentucky, 2014, p. 1827.

FIORIN, José Luiz. Linguagem e interdisciplinaridade. Alea, Rio de Janeiro, v. 10, n. 1, p. 29-53, 2008. DOI: https://doi.org/10.1590/S1517-106X2008000100003.

FREIRE, Paulo. Pedagogia da autonomia: saberes necessários à prática educativa. 25. ed. São Paulo: Editora Paz e Terra, 2002.

FUNDAÇÃO TELEFÔNICA VIVO. Juventude Conectada 2. São Paulo: Fundação Telefônica Vivo, 2015.

GATTI, Bernadete Angelina. Formação de professores no Brasil: características e problemas. Educação \& Sociedade, Campinas, v. 31, n. 113, p. 1355-1379, 2010. DOI: https://doi.org/10.1590/S0101-73302010000400016.

GIACOMAZZO, Graziela Fátima. Rede de formação de professores da educação básica: análise dos princípios organizacionais em cursos de pós-graduação Stricto Sensu. EccoS, São Paulo, n. 37, p. 93-109, maio/ago. 2015. DOI: https://doi.org/10.5585/eccos.n37.5437.

GOMES, Heloisa Maria; MARINS, Hiloko Ogihara. A ação docente na educação profissional. São Paulo: Editora Senac São Paulo, 2004.

HACKETT, Abigail; PAHL, Kate; POOL, Steve. In amongst the glitter and the squashed blueberries: crafting a collaborative lens for children's literacy pedagogy in a community setting. Pedagogies: an international journal. Singapura, 12:1, 58-73, 2017. DOI: https://doi.org/10.1080/1554480X.2017.1283994.

HALL, Stuart. A identidade cultural na pós-modernidade. 6. ed. Rio de Janeiro: DP\&A, 1998. 
HOUAISS. Dicionário eletrônico Houaiss da língua portuguesa. v. 3.0. CD-ROM. São Paulo: Objetiva, 2014.

HUBERMAN, Michael. O ciclo de vida profissional dos professores. In: NÓVOA, Antonio. Vidas de professores. Porto: Porto Editora, 1992, p. 31-61.

INSTITUTO BRASILEIRO DE GEOGRAFIA E ESTATÍSTICA - IBGE. Pesquisa Nacional por Amostra de Domicílios Contínuas (Pnad C). $4^{\circ}$ trimestre de 2016. $21 \mathrm{fev} .2018$.

Disponível em: https://ww2.ibge.gov.br/home/estatistica/pesquisas /pesquisa_resultados.php?id_pesquisa=149. Acesso em: 31 ago. 2021.

ISO 9241:11 (ISO-Internacional Organization for Standartization). Ergonomic requirements for office workwith Visual Display Terminal (VDT). 1998.

KENSKI, Vani Moreira. Tecnologias e tempo docente. Campinas: Editora Papirus, 2013.

KLEIMAN, Ângela (org.). Os significados do letramento. Campinas: Mercado de Letras, 1995.

KLEIMAN, Ângela. Letramento e suas implicações para o ensino de língua materna. Signo. Santa Cruz do Sul, v. 32, n. 53, p. 1-25, dez. 2007. Disponível em: https://online.unisc.br/seer/index.php/signo/article/view/242. Acesso em: 31 ago. 2021.

LANKSHEAR, Colin; KNOBEL, Michele (ed.). Digital literacies: concepts, policies and practices. Nova York: Peter Lang, 2008.

LÉVY, Pierre. Cibercultura. 3. ed. Tradução de Carlos Irineu da Costa. São Paulo: Editora $34,2010$.

LIBÂNEO, José Carlos. Adeus professor, adeus professora? Novas exigências educacionais e profissão docente. São Paulo: Cortez Editora, 1998.

LIJNSE, Pieter Lein. Developmental research as a way to an empirically based didactical structure of science. Science Education, v. 29, n. 2, p. 189-199, 1995. DOI: https://doi.org/10.1002/sce.3730790205.

MARCONI, Marina de Andrade; LAKATOS, Eva Maria. Fundamentos de metodologia científica. 5. ed. São Paulo: Atlas, 2003.

NIELSEN, Jakob. Evaluating hypertext usability. In: JONASSEN, David H.; MANDL, Heinz (eds.). Designing hypermedia for learning. Berlim: Springer-Verlag, 1990, p. 147-168.

NIELSEN, Jakob. Usability engineering. California: Academic Press, 1993.

NÓVOA, Antonio. Formação de professores e formação docente. Os professores e a sua formação. Lisboa: Dom Quixote, 1992, p. 9-33.

NÓVOA, Antonio. Firmar a posição como professor, afirmar a profissão docente. Cadernos de Pesquisa, São Paulo, v. 47, n. 116, out./dez. 2017. DOI:

https://doi.org/10.1590/198053144843. 
OLIVEIRA, Michele Mezari; GIACOMAZZO, Graziela Fátima. Educação e cidadania: perspectivas da literacia digital crítica. EccoS, São Paulo, n. 43, p. 153-174, maio/ago. 2017. DOI: https://doi.org/10.5585/eccos.n43.7393

PETARNELLA, Leandro; SOARES, Maria Lúcia de Amorim. As Tecnologias Midiáticas e Digitais de Informação e Comunicação (TMDICs) e a Educação Contemporânea. EccoS, São Paulo, v. 12, n. 1, p. 181-194, jan./jun. 2010. DOI: https://doi.org/10.5585/eccos.v12i1.2241. PIMENTA, Selma Garrido. Hacia una resignificación de la Didáctica? Ciencias de la Educación, Pedagogía y Didáctica?. Una revisión conceptual y una síntesis provisional. Pedagogia y Saberes, n. 39, p. 117-139, 2013. DOI: https://doi.org/10.17227/01212494.39pys117.139.

PREECE, Jennifer; ROGERS, Yvone; SHARP, Helen. Design de interação: além da interação homem computador. São Paulo: Editora Bookman, 2005.

ROJO, Roxane; MELO, Rosineide de. Letramentos contemporâneos e a arquitetônica Bakhtiniana. Documentação de Estudos em Linguística Teórica e Aplicada - DELTA. São Paulo, v. 33, n. 4, p. 1271-1289, 2017. DOI: https://doi.org/10.1590/0102445057781725543649.

ROSE, David. New developments in genre-based literacy pedagogy. In: MACARTHUR, Charles; GRAHAM, Steve; FITZGERALD, Jill. (eds.). Handbook of Writing Research. 2. ed. New York: Guilford, 2015, p. 11-31.

SANTAELLA, Lucia. A ecologia pluralista da comunicação: conectividade, mobilidade, ubiquidade. São Paulo: Paulus Editora, 2010.

SILIUS, Kirsi; TERVAKARI, Anne-Maritta; POHJOLAINEN, Seppo. A multidisciplinary tool for the evaluation of usability, pedagogical usability, acessibility and informational quality of web-based coursed. Paper presented at the Eleventh International PEG Conference. São Petersburgo, 28 jun.- $1^{\circ}$ jul. 2003. Disponível em:

http://matwww.ee.tut.fi/arvo/liitteet/PEG2003.pdf. Acesso em: 2 dez. 2018.

SILVA, Simone B. da. Da técnica à crítica: contribuições dos novos letramentos para a formação de professores de língua inglesa. São Paulo, 2011. 243 f. Tese (Doutorado em Letras) - Faculdade de Filosofia, Letras e Ciências Humanas, Universidade de São Paulo, São Paulo, 2011.

SILVA, Viviane Gomes da; GOMES, Maria João. Dos dispositivos móveis à aprendizagem ubíqua - da usabilidade técnica à usabilidade pedagógica. Revista de Estudios e Investigación en Psicología y Educación. v. extra, n. 13, p. 211-214, 2015. DOI:

https://doi.org/10.17979/reipe.2015.0.13.610.

SOARES, Magda Becker. Alfabetização: a ressignificação do conceito. Alfabetização e Cidadania, São Paulo, n. 16, p. 9-17, jul. 1998.

SOARES, Magda Becker. Letramento: um tema em três gêneros. Belo Horizonte: Autêntica Editora, 2003. 
SOARES, Magda Becker. Letramento e alfabetização: as muitas facetas. Revista Brasileira de Educação. Rio de Janeiro, n. 25, p. 5-17, jan./abr. 2004. DOI: https://doi.org/10.1590/S141324782004000100002.

SOUZA, Elizeu Clementino de. (Auto)biografia, histórias de vida e práticas de formação. In: NASCIMENTO, Antonio Dias; HETKOWSKI, Tânia Maria. (orgs.). Memória e formação de professores [online]. Salvador: EDUFBA, 2007, p. 59-74.

TARDIF, Maurice; RAYMOND, Danielle. Saberes, tempo e aprendizagem do trabalho no magistério. Educação \& Sociedade, Campinas, v. 21, n. 73, p. 209-244, dez. 2000. DOI: https://doi.org/10.1590/S0101-73302000000400013.

VIEIRA, Ana Maria. A pedagogia social e a mediação na transformação dos olhares patologizadores das diferenças sociais. In: VIEIRA, Ana Maria; VIEIRA, Ricardo (orgs). Pedagogia social, mediação intercultural e (trans)formações. Porto: Profedições, 2016, p. 106-109.

VIEIRA, Ana Maria; VIEIRA, Ricardo. Fronteiras da identidade, mediação intercultural e trânsitos do self. In: NASCIMENTO, Adir Casaro; BECKER, José Licínio (orgs).

Inter/multiculturalidade, relações étnico-culturais e fronteiras da exclusão. Campinas:

Mercado de Letras, 2015, p. 229-258.

WEBSTER, Lee; GUNTER, Helen. How power relations affect the distribution of authority: implications for information literacy pedagogy. Journal of Information Literacy. v. 12, n. 1, p. 68-85, june 2018. DOI: https://doi.org/10.11645/12.1.2306.

ZUIN, Antonio Álvaro Soares. O plano nacional de educação e as tecnologias da informação e comunicação. Educação \& Sociedade, Campinas, v. 31, n. 112, p. 961-980, jul.-set. 2010. DOI: https://doi.org/10.1590/S0101-73302010000300016. 